\title{
An Investigation of the Measurement Estimation Strategies Used by Gifted Students
}

\author{
Fatma ERDOĞAN *1 (D) Tuba ERBEN 2 (D) \\ ${ }^{1}$ Firat University, Faculty of Education, Elazı̆̆, Turkey, f.erdogan@firat.edu.tr \\ ${ }^{2}$ Ministry of National Education, Elazı̆̆, Turkey, tubaerben@outlook.com \\ ${ }^{*}$ Corresponding Author: f.erdogan@firat.edu.tr
}

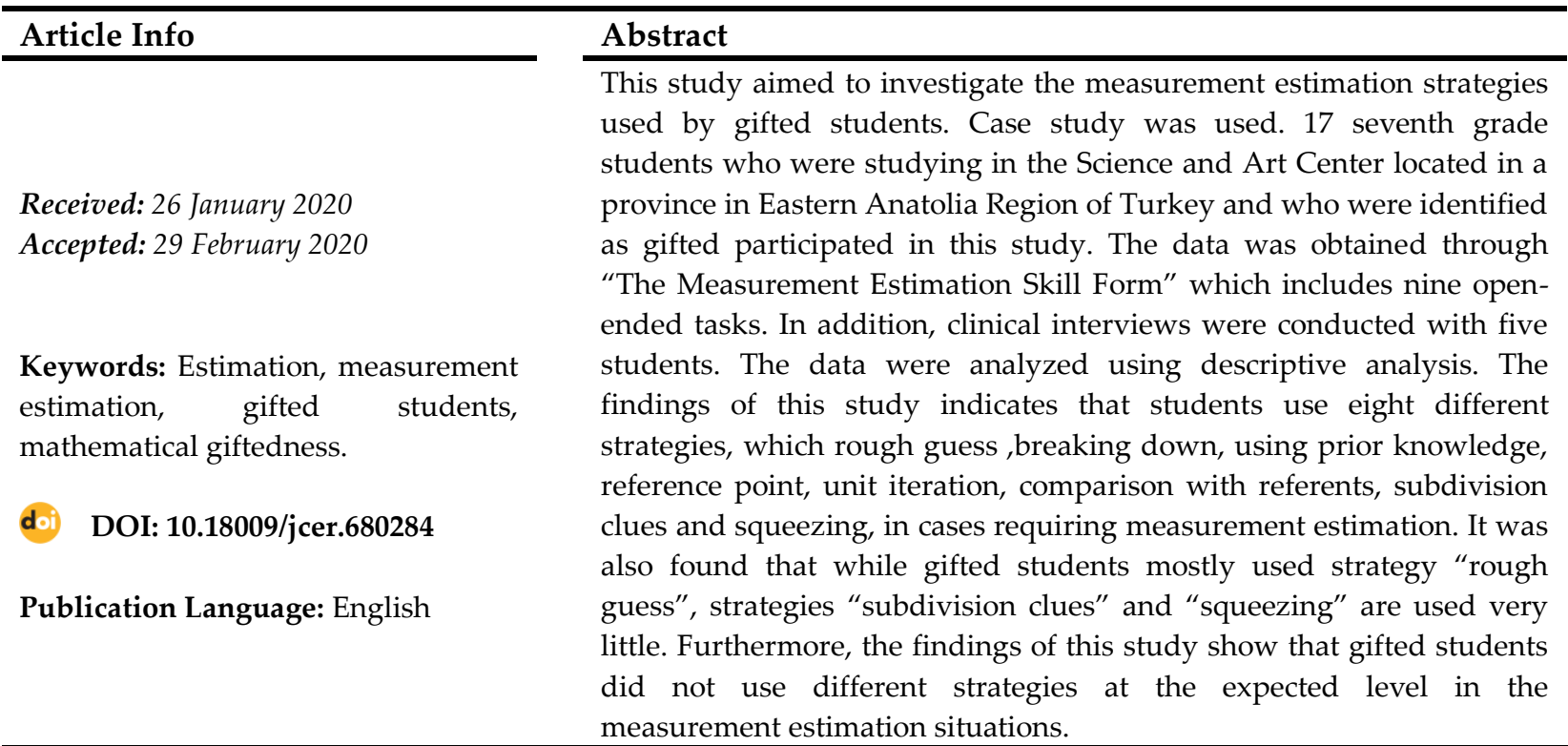

To cite this article: Erdoğan, F. \& Erben, T. (2020). An investigation of the measurement estimation strategies used by gifted students. Journal of Computer and Education Research, 8 (15), 201-223. DOI: $10.18009 /$ jcer. 680284

\section{Introduction}

In recent years, giftedness has been one of the most controversial concepts (Smedsrud, 2018). Different definitions are made about giftedness and gifted students (e.g., Gagne, 2009; Renzulli, 1986). Some of these definitions emphasize the above-average talent, commitment, and creativity (Renzulli, 1986), while others draw attention to the high performance potential of gifted students compared to non-gifted students (Gagne, 2009). In the area of giftedness, one of the controversial issues is whether giftedness is general or subject-specific. Some researchers address giftedness in at least one area, systematically developing, as a specialty (Nolte, 2018). There is no definitive consensus in the definition of the concept of mathematical giftedness involved in these discussions. However, in general, 
mathematical giftedness is accepted as a special part of giftedness (Sheffield, 2018; Singer, Sheffield, Freiman, \& Brandl, 2016).

In the literature, some characteristic features of gifted students are described. Accordingly, it is observed in gifted students to maintain motivation for a long time, to understand complex concepts, to be curious, high observation skills, and extraordinary memory (Freiman, 2018; Gutierrez, Benedicto, Jaime, \& Arbona, 2018, Renzulli, 1986; Singer et al., 2016). In addition, creativity skill is a frequently mentioned concept in personal skills research within personal characteristics about gifted students (Hu, 2019; Karp, 2017; Sheffield, 2018).

Mathematically gifted students show extraordinary advantage in their reasoning and problem solving skills (Singer et al., 2016). The mental flexibility and creativity features of mathematically gifted students have been one of the remarkable topics in recent years (PittaPantazi, Kattou, \& Christou, 2018). In the area of giftedness, there are different opinions about creativity. For example, Usiskin (2000) stated that mathematical creativity covers mathematical giftedness, while some researchers argue that mathematical creativity is a subcomponent of mathematical ability (Sheffield, 2018). Singer et al. (2016), on the other hand, claimed that every student has the capacity of mathematical creativity, regardless of mathematical success or skill level. Also, it is seen that creativity component is included in current mathematical giftedness models (Assmus \& Fritzlar, 2018). Regardless of the size of the discussions, it can be said that creativity is an important factor for mathematically gifted students. In addition, it is seen that both mathematical thinking and creativity include the ability to estimate (Davis \& Rimm, 2004; Starko, 2005; Torrence, 1974). The estimation ability constitudes the context of this study. Thus, the current study will deal with relevant literature on estimation.

\section{What is Estimation?}

In the century we are in, it is considered important that individuals think critically and estimate problems (Sriraman \& Knott, 2009). From this point of view, estimation is considered as one of the basic skills that takes place in the daily lives of both children and adults (National Council of Teachers of Mathematics [NCTM], 2000). Although there are different definitions, the estimation is evaluated as a decision making process. Before the 
decision, processes or measurements are made quickly in the mind, through some procedures or past experiences (Patkin \& Gazit, 2013; Segovia \& Castro, 2009).

The importance of estimation skills is emphasized in many studies in the field of mathematics education (Möhring, Frick, \& Newcombe, 2018; Patkin \& Gazit, 2013; Segovia \& Castro, 2009; Yun-hing, 2007). In studies, it has been stated that estimation skill has beneficial effects on many other mathematical skills such as calculation from mind, spatial and proportional reasoning skills as well as important in daily life (NCTM, 2000; Möhring et al., 2018). It has been determined that estimation activities improve students' understanding of mathematics concepts (Patkin \& Gazit, 2013). It has also been reported that estimation activities can help students develop different strategies in the problem solving process (Singh, Rahmanb, Ramlyc, \& Hoon, 2019). Some researchers, on the other hand, stated that the number sense is related to the estimation (Lemonidis \& Likidis, 2019). Based on all these studies, it can be said that improving the estimation skill can improve other mathematical skills.

In the relevant literature, the estimation skills, which are emphasized to have various benefits, are included in the mathematics curriculum of countries such as the United States, England, and Japan (Liu, 2009; NCTM, 2000). Sowder (1992) stated that estimation skills were included in mathematics education programs in a few sentences before 1980, and that after 1990s, estimation skills started to be focused more on. In Turkey, most recently updated in the mathematics curriculum are mentioned estimation gains and strategies. In addition, the ability to estimation is within the general objectives that the program is trying to achieve (Ministry of National Education [MoNE], 2018).

\section{Measurement Estimation and Its Importance in Mathematics Education}

In the literature, computational and measurement estimation is mentioned (Segovia \& Castro, 2009). Computational estimation is an approximate value that indicates the result of a mathematical operation (Hogan \& Brezinski, 2003). Measurement estimation is the determination of an approximate measurement without a precise measurement process (van de Walle, Karp, \& Williams, 2016). Measurement estimation is the context of this study.

Measurement estimation is the process of measuring or comparing mental and visual information without using measurement tools (van de Walle et al., 2016). Measurement estimation is accepted as one of the basic skills that allow us to understand the world 
(NCTM, 2000). Measurement estimation process is the process of generating subjective judgments or ideas about the measurement of quantities. It is a very common practical skill in everyday life (van de Walle et al., 2016). Joram, Gabriele, Bertheau, Gelman, and Subrahmanyam (2005), on the other hand, emphasized the necessity to make estimations by applying the principles of measurement in cases where there is no physical measurement tool.

Measurement estimation skills of individuals with various professions is very important for their professional lives. For example, an architect needs to guess the gap in which the door will settle (Jones, Taylor, \& Broadwell, 2009). When the literature on mathematics education is examined, it is seen that the measurement estimation skill has benefits in different aspects in the process of learning mathematics. One of them is that measurement estimation has a key role in the process of learning concepts related to measurement (Gooya, Leyla, Khosroshahi, \& Teppo, 2011; Joram et al., 2005). Measurement estimation activities allow students to understand concepts related to measurement and to try measurement skills. At the same time, these activities provide teachers with information on how their students understand the concepts of measurement (Gooya et al., 2011; Usta, 2018).

Numerical skills are also used in activities that compare students' measurement estimation skills. Therefore, measurement estimation activities enable student information to be transferred to other fields of mathematics such as numbers, calculation, fractions, and proportion (Joram et al., 2005). In addition, measurement estimation activities improve students' problem solving skills. Also, these activities enable students to make connections between abstract mathematical ideas and real-life situations (Hodgson, Simonsen, Luebeck, \& Andersen, 2003). In addition to them, measurement estimation is closely related to spatial reasoning skills. Measurement estimation activities also positively affect the development of students' spatial reasoning skills (Hogan \& Brezinski, 2003; Jones, Gardner, Taylor, Forrester, \& Andre, 2012).

\section{Place of Estimation Skills in the Field of Giftedness}

In the area of giftedness, resolving the diverse academic needs of students is one of the topics highlighted (Smedsrud, 2018). In this regard, the implementation of approaches that reveal the intellectual, innovative, and leadership capacity, rather than traditional 
practices, is emphasized in the education of gifted students (Renzulli, 2012). With the development of mathematical creativity, which is one of the basic elements of these approaches, mathematical thinking potentials of gifted students can be supported (Singer et al., 2016).

Mathematical thinking consists of processes such as reasoning, deduction, induction, assumption, generalization, proof, and estimation (Liu \& Niess, 2006). Estimation is an important skill for mathematically gifted students because the concept of creativity, which is closely related to the concept of giftedness, includes estimation skill (Davis \& Rimm, 2004; Torrence, 1974).

In the literature, it has been reported that the most remarkable abilities about creativity are "fluency, flexibility, originality, and elaboration" (Pitta-Pantazi et al., 2018). However, apart from these four abilities, estimation is also stated to be in creative abilities (Davis \& Rimms, 2004). Torrance (1974) stated that the creativity process includes skills such as being sensitive to problems and seeking solutions, making estimations or developing hypotheses for deficiencies. In this regard, Starko (2005) emphasized that both mathematical thinking and creative thinking ability include estimating, generating ideas and developing a multi-faceted perspective on events.

Another relationship between estimation skill and creativity emerges in the process of constructing mathematical concept structures. Estimation is required in the development of rich and flexible mathematical concept structures. Because, estimation plays a role in the development of intuitive, internally born concept structures (Meissner, 2000). Consequently, it is accepted that mathematically gifted students have the ability to estimate within the scope of creativity, which is among the remarkable characteristics.

Special teaching methodologies are required to maintain the interest of mathematically gifted students (Gutierrez et al., 2018). In addition, the design of high quality mathematics lessons for gifted students is related to both the teacher and the content (Leikin, Koichu, Berman, \& Dinur, 2017). Accordingly, it is considered important to design a class discussion regarding estimation strategies. Teachers should help students develop strategies to make estimations. In classroom environments that focus on flexible thinking, not on answers, students will be provided with deep thinking and the development of estimation strategies will be provided (van de Walle et al., 2016). 
Although the estimation is deemed important in terms of mathematical development of gifted students, it is noteworthy that the research on this subject is limited (Akar, 2017; Baroody \& Gatzke, 1991; Dai, Moon, \& Feldhusen, 1998; Montague \& van Garderen; 2003; Wang, Halberda, \& Feigenson, 2017). In some of these studies, measurement skills of gifted students were examined (Baroody \& Gatzke, 1991; Montague \& van Garderen; 2003). In some other studies, the number sense in the context of estimation of gifted students has been considered (Wang et al., 2017). In the studies in the third group, the use of estimation skills in problem solving situations of gifted students was analyzed. In these studies, it has been determined that gifted students make more consistent estimations in the context of mathematical problem solving (Dai et al., 1998). Akar (2017), in her study, stated that gifted students, in the process of solving modeling problems, use estimations as a problem solving strategy.

\section{Purpose and Importance of the Present Study}

Although measurement estimation skill has been proved to have positive contributions to mathematical development, there is a lack of studies focusing on this topic (Hartono, 2015; Jones et al., 2009; 2012). A similar situation is observed in studies conducted in Turkey. A limited number of studies investigating estimation skill have been found since 2000 (Boz-Yaman \& Bulut, 2017). In these studies, predominantly on computational estimation skill, therefore it was determined that the number sense was addressed (Aytekin \& Toluk-Uçar, 2014). Studies on estimation skills have been found to be limited (e.g., Kılıç \& Olkun, 2013).

The literature on gifted students and mathematics education also shows that there are limited number of international studies on the estimation skills of gifted students (e.g., Baroody \& Gatzke, 1991; Dai et al., 1998; Montague \& van Garderen; 2003; Wang et al., 2017). In addition, no study that has paid attention to estimation skills of gifted students can be found in Turkey. In the studies conducted in the field of giftedness, it is stated by the researchers that the learning and mathematical thinking processes of the gifted students are not examined sufficiently (Sheffield, 2018; Wang et al., 2017). This requires investigation of estimation skills of gifted students. The present study focused on the strategies used by gifted students in measurement estimation tasks. Therefore, this study is important since it bridges an important gap in the literature on giftedness and mathematics education. 
Estimation skill is within the abilities that express mathematical giftedness (Davis \& Rimm, 2004). Also, measurement estimation is an important real-life skill (Gooya et al., 2011; van de Walle et al., 2016). Accordingly, determining the measurement estimation performances of the gifted students is considered to have a crucial importance. The results of this study are expected to contribute to the awareness of the gifted students' measurement estimation skills. It is also thought that the results of this study will be a starting point for the researchers who will carry out studies on this topic.

Teachers are required to have knowledge about the estimation ability and to design a teaching environment based on this information (Boz-Yaman \& Bulut, 2017). In addition, it is clear that gifted students have different needs in mathematics education than their peers (Gutierrez et al., 2018; Hu, 2019; Smedsrud, 2018). Teacher competencies are an important factor in meeting these learning needs (Leikin et al., 2017). Based on this information, the current study is expected to provide teachers with information about the estimation strategies used by gifted students. In addition, these study findings are thought to present new ideas to teachers in designing measurement estimation tasks for gifted students.

Developing differentiated mathematics programs to meet the needs of gifted students is one of the topics highlighted in recent years ( $\mathrm{Hu}, 2019$; Sheffield, 2018). However, in Turkey, the development of special programs for gifted students appears to be insufficient (Özçelik, 2017). The current findings of this study may provide program development experts with an understanding into the process of designing tasks for estimation skill. Motivated by the aforementioned concerns, this study aimed to investigate the measurement estimation strategies used by gifted students. Within the scope of the study, the answer to the question "What are the measurement estimation strategies used by gifted students in real life situations?" was sought.

\section{Methodology}

Model

Case study was used in the study. Case study is an empirical inquiry that examines a current phenomenon in its real-life context (Yin, 2017, p. 16). While gifted students are the analysis unit of the study, the measurement estimation strategies used by gifted students constitute the analyzed situation. 


\section{Participants}

17 seventh grade students who were studying in the Science and Art Center located in a province in Eastern Anatolia Region of Turkey and who were identified as gifted participated in this study. Participants of the study were determined by appropriate sampling method since they are easily accessible. Conducting the study has become easier with the appropriate sampling method (Mcmillan \& Schumacher, 2010). The reason why the participants were selected among seventh grade students is that they have seen the estimation gains in the mathematics curriculum at previous grade levels. Totally 21 seventh grade students are enrolled in the Science and Art Center. However, two students with a talent field "painting" and two students who were absent could not be taken as participants of the study. All of the participants were educated in the Science and Art Center in their city, within the scope of the program to realize their individual talents. In addition, six of the students were female (35\%) and 11 were male (65\%). Eight of the students were in public secondary school, and nine were in a private secondary school.

In the second sampling process, five gifted students were determined by purposeful sampling method. Among the purposeful sampling methods, according to the criterion sampling, the participants were included in the group according to the predefined criteria (Patton, 2002). Accordingly, the number of using different strategies was taken as a criterion. The aim is to obtain detailed information on different strategies. Accordingly, clinical interviews were conducted with five gifted students who use the most different strategies. Throughout the whole study, gifted students were provided on a voluntary basis. In the findings part of the study, the term "students" was used in order to ensure fluency instead of gifted students.

\section{Data Collection Tools}

The data was obtained through "Measurement Estimation Skill Form (MESF)" which includes nine open-ended tasks. In the selection of the tasks, studies related to the measurement estimation skill were used (e.g., Gooya et al., 2011; Hogan \& Brezinski, 2003; Kılıç \& Olkun, 2013; Montague \& van Garderen, 2003; van de Walle et al., 2016). While determining the tasks, the achievements of mathematics curriculum (MoNE, 2018) were also taken into consideration. In MESF, there were a total of nine tasks, requiring an estimate of the width and height of objects (tasks 2, 3, 4, and 6), areas (tasks 1 and 8), volumes (tasks 5 
and 7), and weights (task 9). The length-related tasks are often due to the fact that the studies in the literature are mostly done on length estimation (Desli \& Giakoumi, 2017; Jones et al., 2009; Hartono, 2015). In this study, by preparing tasks in different contexts related to length estimation, diversity in students' estimation strategies was determined.

MESF was presented to the opinion of four specialist faculty members (who had studies in mathematics education and special education) and three mathematics teachers (one of the teachers working in secondary school and two of the teachers working in Science and Art Center). According to the specialist and teacher feedback, it was determined that the MESF was appropriate for the student level and the purpose of the study. In addition, MESF was applied as a pilot study to two seventh grade students who were not study participants. At the end of the pilot study, it has been determined that the duties are understandable and the MESF is applicable. Besides, the purpose of considering the mathematics curriculum and studies in the literature is to raise the validity of the tasks.

Clinical interviews were also conducted with students in order to reach more detailed data and support the study, which are used by gifted students in measurement estimation tasks. Clinical interview is a mutual interview to examine thoughts in depth and to investigate the structure of information (Clement, 2000). During clinical interviews, gifted students were shown their responses to the tasks in the MESF, and they were asked to explain their responses to each task. In addition, additional questions were asked (e.g., how?, why?). The interview with each gifted student took about 20 minutes, the interview was recorded with a voice recorder.

\section{Data Analysis}

The data were analyzed using descriptive analysis. First, studies on measurement estimation strategies were examined (e.g., Desli \& Giakoumi, 2017; Gooya et al., 2011; Hartono, 2015; Jones et al., 2009; 2012; Joram et al., 2005; Kılıç \& Olkun, 2013; Segovia \& Castro, 2009; van de Walle et al., 2016). Then, the measurement estimation strategies that can be revealed in these studies were found out by two experts and a framework was formed. Student responses were coded according to this framework, and the findings became clear. The strategies and explanations that emerged in student responses are given in Table 1. 
Table 1. Strategies and explanations used in measurement estimation tasks

\begin{tabular}{|c|c|c|}
\hline Strategy & Explanation & Instance \\
\hline $\begin{array}{l}\text { Reference point } \\
\text { (mental ruler/ } \\
\text { benchmark/ } \\
\text { individual frames } \\
\text { of reference) }\end{array}$ & $\begin{array}{l}\text { This strategy is for students to estimate the } \\
\text { measurements of other objects by taking } \\
\text { advantage of the measurements of the objects } \\
\text { they knew well before. In this strategy, the } \\
\text { student makes a measurement estimation } \\
\text { using a mental image of a non-standard unit. }\end{array}$ & $\begin{array}{l}\text { If there is a pencil that the student } \\
\text { knows the length of, the student can } \\
\text { estimate the length of any box by } \\
\text { comparing it with the length of the } \\
\text { pencil. }\end{array}$ \\
\hline $\begin{array}{l}\text { Using prior } \\
\text { knowledge }\end{array}$ & $\begin{array}{l}\text { In this strategy, the student needs to know in } \\
\text { advance about the length, area, or volume } \\
\text { measure of the object to be estimated. The } \\
\text { student makes measurement estimations } \\
\text { about the object by using his prior } \\
\text { knowledge. }\end{array}$ & $\begin{array}{l}\text { In the task of estimating the height of a } \\
\text { multi-storey building, the student } \\
\text { makes the estimation, using this } \\
\text { information, if student knows in } \\
\text { advance that the height of a floor is } \\
\text { three meters. }\end{array}$ \\
\hline Unit iteration & $\begin{array}{l}\text { With the unit iteration strategy, the student } \\
\text { mentally or physically performs the } \\
\text { measurement estimation of the object by } \\
\text { repeating a standard unit. }\end{array}$ & $\begin{array}{l}\text { The student guesses by repeating the } \\
\text { movements of one hand while } \\
\text { estimating the length of the blackboard. }\end{array}$ \\
\hline $\begin{array}{l}\text { Comparison with } \\
\text { referents }\end{array}$ & $\begin{array}{l}\text { It is the comparison of physically existing or } \\
\text { abstract objects with the measure of the object } \\
\text { to be estimated. Although the student's prior } \\
\text { knowledge is important, expressions such as } \\
\text { "equal, greater or smaller" can be used. }\end{array}$ & $\begin{array}{l}\text { It is a student who guesses the height of } \\
\text { a tree, saying that the height of the tree } \\
\text { is equal to the height of the school. }\end{array}$ \\
\hline Squeezing & $\begin{array}{l}\text { The compression strategy is placing the size } \\
\text { of the object whose size is to be estimated, } \\
\text { between the two measures. }\end{array}$ & $\begin{array}{l}\text { The student expresses that the length of } \\
\text { the object related to a measurement } \\
\text { with a length of } 70 \mathrm{~cm} \text { is between half a } \\
\text { meter and a meter. }\end{array}$ \\
\hline Break & $\begin{array}{l}\text { The breaking down strategy is to estimate the } \\
\text { size of the object using smaller, equal, or } \\
\text { unequal parts. }\end{array}$ & $\begin{array}{l}\text { In the case of estimating the length of a } \\
\text { wall, the length of the wall is to } \\
\text { estimate the length of the shorter } \\
\text { sections, such as windows, boards, } \\
\text { located along the wall. }\end{array}$ \\
\hline Subdivision clues & $\begin{array}{l}\text { This strategy is similar to the breaking down } \\
\text { strategy. However, in the subdivision clues } \\
\text { strategy, there are no useful sections to } \\
\text { estimate the size of the object, and the } \\
\text { student mentally divides the object into } \\
\text { pieces. }\end{array}$ & $\begin{array}{l}\text { In the task of estimating the length of a } \\
\text { wall, the wall is divided into two, then } \\
\text { four, and eight, and the estimate is } \\
\text { made. }\end{array}$ \\
\hline Rough guess & $\begin{array}{l}\text { In the rough guess strategy, the student does } \\
\text { not express what he/she has guessed. }\end{array}$ & $\begin{array}{l}\text { The student explains his/her estimation } \\
\text { on grounds such as "I looked at the eye } \\
\text { (eyeballed it)" or "I made a guess". }\end{array}$ \\
\hline
\end{tabular}

In addition to the measurement estimation strategies given in Table 1, unanswered tasks were coded "unanswered". In order to determine the reliability of the study, compatibility between coders was calculated (Miles, Huberman, \& Saldana, 2014). Accordingly, student responses were independently coded according to the strategies determined by the two researchers in line with the theoretical framework. Compatibility between encoders was calculated as $89 \%$. Compatibility between coders is expected to be at least $80 \%$ (Miles et al., 2014). In the current study, although the percentage of coding compatibility was considered sufficient for reliability, the researchers discussed on 
incompatible codes until they reached a common view. In addition, direct transfers were made from participant responses. While presenting the findings, instead of the real names of the students, coding was done in the form of "S1 (first-line student)".

\section{Findings}

In this part of the study, the analysis results of the data obtained from MESF are presented. First of all, in situations that require students' measurement estimation, the measurement estimation strategies they use are examined on a task basis, and their strategy distributions are given in Table 2.

Table 2. Distribution of measurement estimation strategies used by students by tasks

\begin{tabular}{|c|c|c|c|c|c|c|c|c|c|c|c|c|c|c|c|c|c|c|c|c|c|c|}
\hline$\frac{\breve{y}}{\stackrel{\widetilde{J}}{\oplus}}$ & 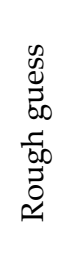 & & 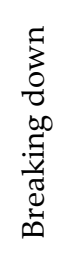 & & 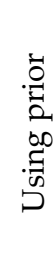 & & 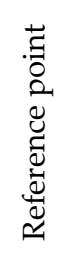 & & 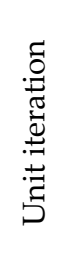 & & 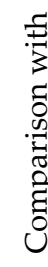 & 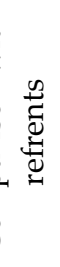 & 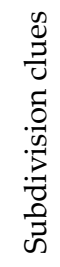 & & 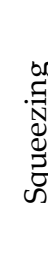 & & 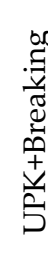 & & $\frac{v}{6}$ & & 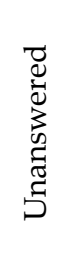 & \\
\hline & $\mathrm{f}$ & $\%$ & $\mathrm{f}$ & $\%$ & $\mathrm{f}$ & $\%$ & $\mathrm{f}$ & $\%$ & $\mathrm{f}$ & $\%$ & $\mathrm{f}$ & $\%$ & $\mathrm{f}$ & $\%$ & $\mathrm{f}$ & $\%$ & $\mathrm{f}$ & $\%$ & $\mathrm{f}$ & $\%$ & $\mathrm{f}$ & $\%$ \\
\hline 1 & 3 & 18 & 0 & 0 & 1 & 6 & 0 & 0 & 3 & 18 & 0 & 0 & 6 & 35 & 0 & 0 & 0 & 0 & 4 & 24 & 0 & 0 \\
\hline 2 & 2 & 12 & 10 & 59 & 1 & 6 & 0 & 0 & 0 & 0 & 2 & 12 & 0 & 0 & 0 & 0 & 1 & 6 & 0 & 0 & 1 & 6 \\
\hline 3 & 7 & 41 & 0 & 0 & 0 & 0 & 4 & 24 & 1 & 6 & 4 & 24 & 0 & 0 & 0 & 0 & 0 & 0 & 0 & 0 & 1 & 6 \\
\hline 4 & 12 & 71 & 1 & 6 & 0 & 0 & 3 & 18 & 0 & 0 & 0 & 0 & 0 & 0 & 0 & 0 & 0 & 0 & 0 & 0 & 1 & 6 \\
\hline 5 & 11 & 65 & 0 & 0 & 0 & 0 & 1 & 6 & 1 & 6 & 2 & 12 & 0 & 0 & 2 & 12 & 0 & 0 & 0 & 0 & 0 & 0 \\
\hline 6 & 3 & 18 & 0 & 0 & 0 & 0 & 5 & 29 & 6 & 35 & 0 & 0 & 0 & 0 & 0 & 0 & 1 & 6 & 0 & 0 & 2 & 12 \\
\hline 7 & 4 & 24 & 0 & 0 & 9 & 53 & 0 & 0 & 0 & 0 & 0 & 0 & 0 & 0 & 0 & 0 & 0 & 0 & 0 & 0 & 4 & 24 \\
\hline 8 & 3 & 18 & 10 & 59 & 3 & 18 & 0 & 0 & 0 & 0 & 0 & 0 & 0 & 0 & 0 & 0 & 1 & 6 & 0 & 0 & 0 & 0 \\
\hline 9 & 16 & 94 & 0 & 0 & 1 & 6 & 0 & 0 & 0 & 0 & 0 & 0 & 0 & 0 & 0 & 0 & 0 & 0 & 0 & 0 & 0 & 0 \\
\hline 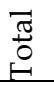 & 61 & & 21 & & 15 & & 13 & & 11 & & 8 & & 6 & & 2 & & 7 & & 4 & & 9 & \\
\hline
\end{tabular}

According to Table 2, a total of 144 answers were obtained in the measurement estimation tasks, whereas 9 tasks were not answered. It was found that students use eight different strategies, namely rough guess, breaking down, using prior knowledge, reference point, unit iteration, comparison with referents, subdivision clues and squeezing, in cases requiring measurement estimation. In addition, it has been determined that some students use two strategies together. The strategies used together are "using prior knowledge + breaking down" and "using prior knowledge + subdivision clues".

"Rough guess" strategy appeared to be the most used strategy of the students $(\mathrm{f}=61)$. The rough strategy is followed by "breaking down" ( $\mathrm{f}=21)$ and "using prior knowledge" 
$(\mathrm{f}=15)$ strategies, respectively. "Squeezing" strategy was found to be the least used strategy $(\mathrm{f}=2)$. In addition, the "subdivision clues" strategy was shown to be one of the less preferred strategies $(\mathrm{f}=6)$.

After the measurement estimation strategies are analyzed on a task basis, the number of different strategies used by each student is analyzed and the results are shown in Table 3. At the end of this analysis, clinical interviews were made with S1, S5, S10, S14, and S17 which uses the most strategy.

Table 3. Number of measurement estimation strategies students use

\begin{tabular}{ll}
\hline Number of strategies & Student \\
\hline 1 & S2 \\
2 & S3 \\
3 & S4, S9, S12 \\
4 & S6, S7, S13, S15, S16 \\
5 & S8, S11, S14 \\
6 & S5 \\
7 & S1, S10, S17 \\
\hline
\end{tabular}

The distribution of the students' measurement estimation strategies according to the tasks reveals that that the strategies varied according to the tasks. In the first task, "subdivision clues" (35\%) and "using prior knowledge + subdivision clues" (24\%) strategies came to the fore. In strategy "subdivision clues", the students made the estimate by dividing the rectangle into pieces to estimate the area of the rectangle. The statements of S1 using this strategy and the drawing for the task are given below.

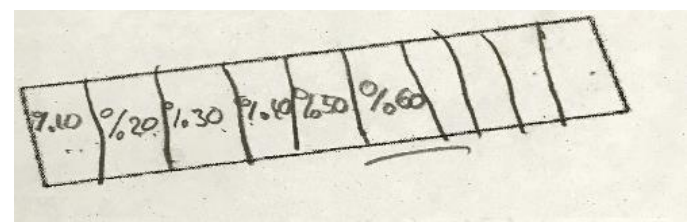

Figure 1. Student's (S1) estimation using the strategy of subdivision clues

Task 1: If you want to estimate $60 \%$ of the area of the given rectangle, what kind of path do you follow?

I (Interviewer): Can you explain how you estimate $60 \%$ of the area of the given rectangle?

S1: Before I guessed the area, I thought I might do what. Then I said piece by piece, slice slice.

I: You thought so well. So, what did you pay attention to while doing this?

S1: Hmm. I paid attention that my pieces are equal. So, as much as I can. But by counting 10, 20, 30, I got my pieces to $60 \%$.

In the second and eighth tasks, more than half of the students (59\%) were observed to use the "breaking down" strategy. "Beraking down" strategy was similar to strategy "subdivision clues". However, the main difference between the two strategies was that in 
"breaking down" strategy, there were useful parts to estimate the size of the object. Accordingly, it has been observed that students make their estimaitons in the second and eighth tasks, using unit squares and dotted paper as useful sections. In the second task, the statements of S10 using the breaking down strategy and the drawing for the task are presented below.

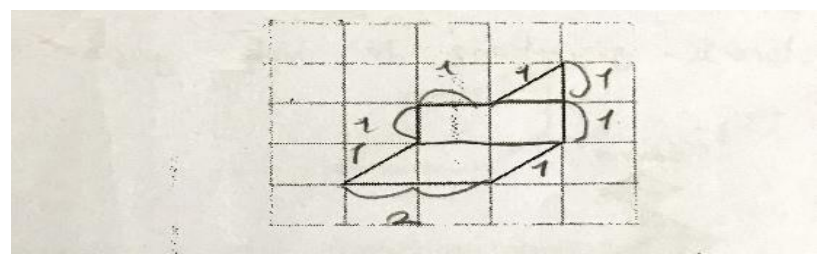

Figure 2. Student's (S10) estimation using the strategy of breaking down

Task 2: If you want to estimate the circumference of the given shape, what kind of path do you follow? Estimate the circumference of the shape according to this path you follow.

I: You have been asked to estimate the length of the perimeter of the shape. You guessed it that way. Can you tell me how you guessed it?

S10: Here I thought of the spacing of the squares. If I consider the vertical and horizontal, the same... ummmmm (counts every piece that forms the perimeter of the shape), its circumference is nine centimeters.

I: So, what do you pay attention to when using the spacing of the squares to guess?

S10: I pay attention to the equal intervals. But wait a minute! Will the curves be the same, which?

I: Why do you think so?

S10: As if the curves may be different (student thinks). But the guess is already. Approximately, it will be like this.

In the eighth task, the statements of S5 using the "breaking down" strategy and the drawing for the task are presented below.

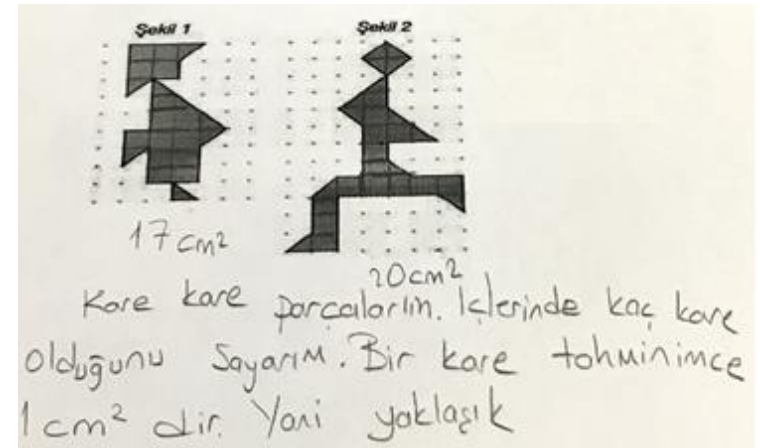

(Content of student response: I smash squares. I count how many squares are in them. I guess a square is $1 \mathrm{~cm}^{2}$. That is, about...)

Figure 3. Student's (S5) estimation using the strategy of breaking down 
Task 8: If you want to estimate the area of the given shape, what kind of path do you follow? Estimate the area of the shape according to this path you follow.

I: You have been asked to guess the areas of the shapes. Can you tell me how he made his estimations?

S5: If I think of dots as a unit square, so if I draw... (student thinks). By dividing the whole shape into rectangles, triangles and squares, I made my job easier.

I: Why did you try to divide it into a rectangle?

S5: It is not rectangular, in fact, it seems more accurate if I say square. I divided the whole shape into rectangles and triangles first. Then I cut the rectangle into squares. I counted the squares I found, half of the number of triangles, I added.

In the third, fourth, and fifth tasks, it was determined that mostly the "rough guess" strategy was used ( $41 \%$ for third task, $71 \%$ for fourth task, and $65 \%$ for fifth task). Students using the "rough guess" strategy do not provide a justification for their estimations. In the third task, the clinical interview and sample estimations of S14 using the rough guess strategy are presented.

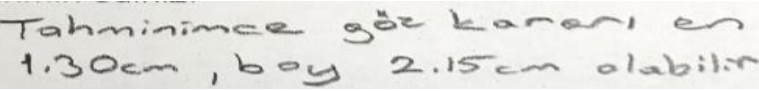

(Content of student response: I guess, the eye decision can be $1.30 \mathrm{~cm}$ wide and $2.15 \mathrm{~cm}$ tall.)

Figure 4. Student's (S1) estimation using the strategy of rough guess for third task

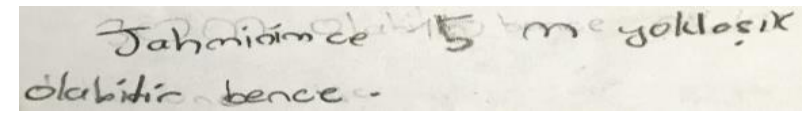

(Content of student response: I guess it can be $5 \mathrm{~m}$, in my opinion.)

Figure 5. Student's (S17) estimation using the strategy of rough guess for fourth task

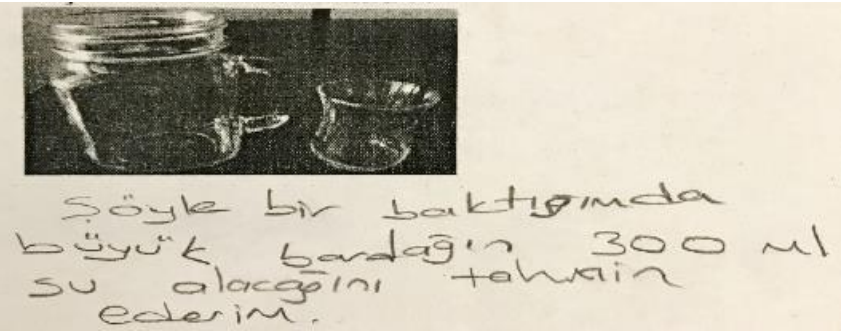

(Content of student response: When I look at this, I guess that the big glass will take $300 \mathrm{ml}$ of water.)

Figure 6. Student's (S14) estimation using the strategy of rough guess for fifth task

Task 3: Estimate the width and length of the door of the class you are in.

Task 4: How tall is the Science and Art Center building?

Task 5: The small glass takes $90 \mathrm{ml}$ of water. Accordingly, how many milliliters of water does the other glass on the table take?

I: The small glass provided takes $90 \mathrm{ml}$ of water. Accordingly, in the question of how many $\mathrm{ml}$ of water the glass will take, can you explain its estimation? 
S14: Hmm. I guess it might be $300 \mathrm{ml}$.

I: Why do you think so?

S14: When I think of the glasses, I found it like this.

I: Can you explain how you got the result?

S14: If I said $500 \mathrm{ml}$, it would be too much. I guess it would be like this.

In the sixth task, the "unit iteration" strategy is the most used strategy (35\%). In the "unit iteration" strategy, students counted repetitive units, physically or mentally, to estimate the size of an object. The statements of S17 using the unit iteration strategy and the drawing Figure 7 for the task are presented below.

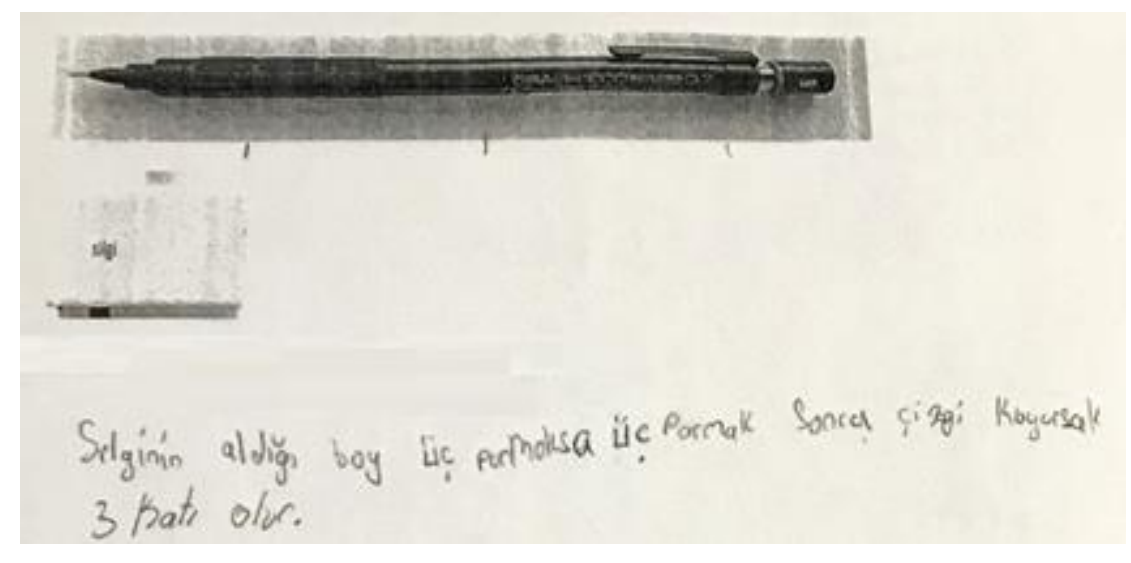

(Content of student response: If the length of the eraser is three fingers, if we put a line after three

$$
\text { fingers, it will be } 3 \text { times.) }
$$

Figure 7. Student's (S17) estimation using the strategy of unit iteration

Task 6: How many erasers does the length of the pencil given above correspond to? Please explain.

I: The length of the pencil is how many eraser lengths are asked. Can you explain what you think and how you estimated it?

S17: First, I measured the length of the eraser with my fingers, then I measured the length of the pen with my fingers, and I saw that the pen was 3 times the length of the eraser.

I: What did you pay attention to while doing this?

S17: Since I measured using one finger of my left hand, 2 fingers of my right hand, I was careful not to confuse the measurements.

In the seventh task, more than half of the students used the "using prior knowledge" strategy (59\%). In this strategy, students have made an estimate of the object to be measured using the knowledge they have. The statements for clinical interview of the student (S10) applying "using prior knowledge" strategy and Figure 8 for the task are presented below. 


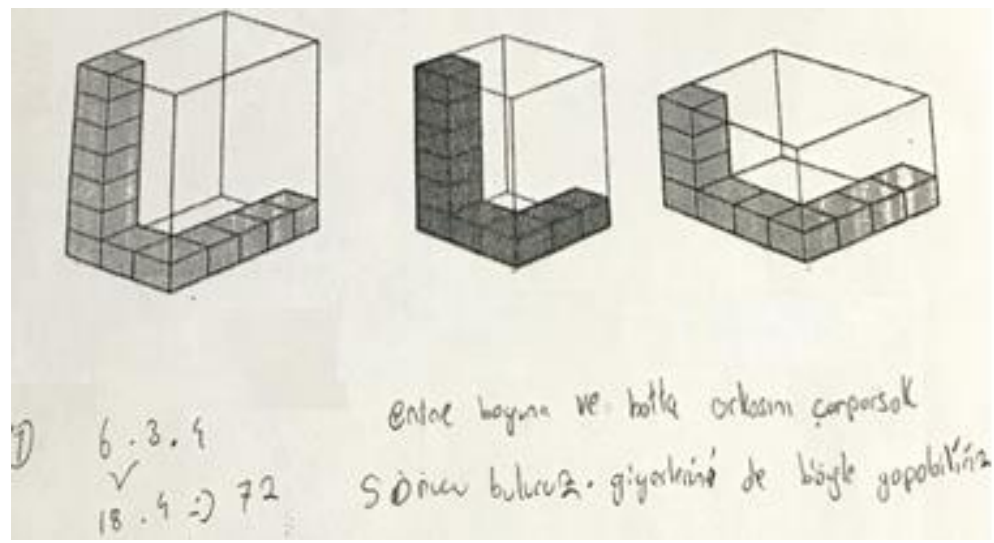

(Content of student response: If we multiply transversely, longitudinally or even back, we will find the result. We can do the others like that.)

Figure 8. Student's (S10) estimation using the strategy of using prior knowledge

Task 7: If you want to estimate the number of unit cubes that make up the prisms above, what kind of way do you follow? Estimate the number of cubes per unit according to this path.

I: In this task, you have been asked to estimate the number of unit cubes that make up the prisms. Can you tell me what you think?

S10: Yes, not all cubes were given (student thinks). In fact, we can estimate the prism without filling all of the cubes per unit.

I: How can you do that?

S10: We find the width, length and even the dimensions of the back of the prism as an estimate if we multiply it.

G: Why are you multiplying these measures?

S10: Because if you fill the cubes, there will be volume. Each unit cube will yield a volume. With width and length, I find the base length, then, up to the top, I look. In fact, asking for the volume.

In the ninth task, almost all of the students preferred the "rough guess" strategy (94\%). The ninth task is, "10 medium-sized tomatoes, how many kg?" In the ninth task requiring weight estimation, it was determined that students generally use the "rough guess" strategy.

\section{Discussion, Conclusion, and Recommendation}

In this study investigated the measurement estimation strategies used by gifted students. The findings of this study indicates that gifted students use eight different strategies, which rough guess, breaking down, using prior knowledge, reference point, unit iteration, comparison with referents, subdivision clues and squeezing, in cases requiring measurement estimation. It was determined that some students used two strategies together, 
"using prior knowledge + breaking down" and "using prior knowledge + subdivision clues". It was found that very few students left the tasks unanswered.

In accordance with findings, it was also found that while gifted students mostly used strategy "rough guess", strategies "subdivision clues" and "squeezing" are used very little. In addition, it was concluded that gifted students used different strategies in tasks requiring length, area, volume and weight estimation. It is thought that this finding is related to the context of the tasks demanded from the gifted students and their experiences. Previous studies support this notion (Gooya et al., 2011; Jones et al., 2012). Gooya et al. (2011) stated that students use different strategies depending on the context in situations that require measurement estimation. Jones et al. (2012), on the other hand, stated that their students' estimation performance is related to their past lives.

A remarkable result reached in the study is that gifted students use the "rough guess" strategy intensively. In the "rough guess" strategy, there is no justification for how the estimate is made (Gooya et al., 2011). Estimation skill is related to creativity, which is one of the important characteristic features of gifted students (Davis \& Rimm, 2004; Torrance, 1974). Therefore, it is an expected situation that gifted students use more different estimation strategies. However, this result of the study may be due to the fact that gifted students did not have enough experience and developed different strategies with their measurement estimation activities. Based on this idea, it is suggested to design learning environments where gifted students can discuss different measurement estimation strategies. In addition, it is expected that studies examining the effects of various learning methods and techniques on measurement estimation strategies used by gifted students are expected.

The findings of this study show that gifted students did not use different strategies at the expected level in the measurement estimation situations. This result of the study is consistent with the findings of Montague and van Garderen (2003). Montague and van Garderen (2003) stated that gifted students had low "numerosity estimation" performances. Numerosity estimation is evaluated in measurement estimation (Segovia \& Castro, 2009). However, it was determined that this result obtained in the study differed from the results of Baroody and Gaztzke (1991). The researchers had revealed that gifted students showed success in terms of measurement estimation. This difference in study results may have resulted from the sample. Because, one of these studies included preschool students (Baroody \& Gaztzke, 1991), while the other study included secondary school students 
(Montague \& van Garderen, 2003). Based on this result, it can be said that more studies are needed that involve different grade levels related to gifted students' measurement estimation skills.

In the literature, it is emphasized that the studies on mathematics education with gifted students are inadequate (Sheffield, 2018; Singer et al., 2016; Wang et al., 2017). In this regard, Leikin (2011) states that mathematics education is not adequately represented in the giftedness literature. However, studies examining the estimation ability of gifted students are quite limited (e.g., Baroody \& Gatzke, 1991; Dai et al., 1998; Montague \& van Garderen; 2003). Therefore, it can be said that there is not enough knowledge accumulating the results of the current study, which would allow for a more detailed discussion. However, comparisons can be made with studies conducted with non-gifted students. Accordingly, differences are observed in the measurement estimation strategies frequently used by gifted students and non-gifted students. Gooya et al. (2011) stated that students mostly use the "comparison with referents", "using prior knowledge", and "reference point" strategies. Joram et al. (2005), on the other hand, talked about the "unit iteration" strategy being used frequently. Both Joram et al. (2005) and K1lıç and Olkun (2013) found that the "refence point" strategy was not used frequently.

As participants of this study, only the handling of seventh grade students can be considered as the limitation of the study. However, gender differences and age (grade level) variables are frequently examined in the literature on mathematics education. In studies examining students' estimation skills, the age and gender variable is considered important (Aytekin \& Toluk-Uçar, 2014; Jones et al., 2012; Yun-hing, 2007). Accordingly, the future studies may address the issue whether the gifted students' measurement estimation skills differ according to age and gender. Also, the future studies can examine the accuracy of the gifted students' measurement estimation results.

In studies conducted with non-gifted students, it has been determined that the measurement estimation skill is related to motivation, conceptual knowledge and spatial reasoning skills (e.g., Jones et al., 2012; Hogan \& Brezinski, 2003). From this point forth, the future studies should also focus on variables such as motivation, spatial reasoning skill, which are thought to be related to students' computational or measurement estimation skills. In addition, it is recommended to conduct studies to examine the computational estimation skills and number sense of gifted students. 
Teacher competencies are an important factor affecting the math learning processes of gifted students (Gutierrez et al., 2018; Leikin et al., 2017). In order to respond to the needs of gifted students, which differ from other students, there is a need for teachers who have indepth knowledge and talent in their field (Subotnik, Olszewski-Kubilius, \& Worrell, 2011). In addition, one of the reasons for the low performance of students' estimation is the teacher competencies (Desli \& Giakoumi, 2017). Based on this information, studies examining the measurement estimation skills of mathematics teachers who deliver instruction to gifted students can also be carried out. Thus, necessary precautions can be planned by seeing the deficiencies of the teachers. Finally, it is suggested that mathematics teachers working with gifted students should be provided with seminars, courses or in-service trainings on topics such as mathematical creativity and estimation skills.

\section{Acknowledgement}

The earlier version of this paper was presented at International Congress on Gifted and Talented Education at Inönü University, Malatya-Turkey (November 1-3, 2019).

The data used in this study was confirmed by the researchers that it belongs to the years before 2020.

Authorship Contribution Statement

Fatma ERDOĞAN: Conceptualization, design of the work, literature search, data analysis, data interpretation, writing - review and editing.

Tuba ERBEN: Conceptualization, data collection, preliminary analyses, manuscript draft, writing, manuscript revision

\section{References}

Akar, Ş. Ş. (2017). Üstün yetenekli öğrencilerin matematiksel yaratıcılıklarının matematiksel modelleme etkinlikleri sürecinde incelenmesi [Examining mathematically gifted students' mathematical creativity through the process of model eliciting activities] (Unpublished doctoral dissertation). Hacettepe University, Ankara.

Assmus, D., \& Fritzlar, T. (2018). Mathematical giftedness and creativity in primary grades. In F. M. Singer (Ed.), Mathematical creativity and mathematical giftedness: Enhancing creative capacities in mathematically promising students (pp. 373-404). New York: Springer.

Aytekin, C., \& Toluk-Uçar, Z. (2014). Investigation of middle school students' estimation ability with fractions. Elementary Education Online, 13(2), 546-563. 
Baroody, A. J., \& Gatzke, M. R. (1991). The estimation of set size by potentially gifted kindergarten-age children. Journal for Research in Mathematics Education, 22(1), 59-68.

Boz-Yaman, B., \& Bulut, S. (2017). Middle school mathematics teachers' opinions on estimation. Necatibey Faculty of Education Electronic Journal of Science and Mathematics Education, 11(1), 48-80.

Clement, J. (2000). Analysis of clinical interviews: Foundations and model viability. In A. E. Kelly \& R. A. Lesh (Eds.), Handbook of research design in mathematics and science education (pp. 547-589). London: Lawrence Erlbaum Associates, Publishers.

Dai, D. Y., Moon S. M., \& Feldhusen, J. F. (1998). Achievement motivation and gifted students: A social cognitive perspective. Educational Psychologist, 33(2-3), 45-63.

Davis, G. A., \& Rimm, S. B. (2004). Education of the gifted and talented. Boston, MA: Pearson Education Press.

Desli, D., \& Giakoumi, M. (2017). Children's length estimation performance and strategies in standard and non-standard units of measurement. International Journal for Research in Mathematics Education, 7(3), 61-84.

Freiman, V. (2018). Complex and open-ended tasks to enrich mathematical experiences of kindergarten students. In F. M. Singer (Ed.), Mathematical creativity and mathematical giftedness: Enhancing creative capacities in mathematically promising students (pp. 373-404). New York: Springer.

Gagné, F. (2009). Building gifts into talents: Detailed overview of the DMGT 2.0. In B. MacFarlane \& T. Stambaugh (Eds.), Leading change in gifted education: The Festschrift of Dr. Joyce Vantassel-Baska (pp. 61-80). Waco, TX: Prufrock Press.

Gooya, Z., Khosroshahi, L. G., \& Teppo, A. R. (2011). Iranian students' measurement estimation performance involving linear and area attributes of real-world objects. ZDM Mathematics Education, 43(5), 709-722.

Gutierrez, A., Benedicto, C., Jaime, A., \& Arbona, E. (2018). The cognitive demand of a gifted student's answers to geometric pattern problems. In F. M. Singer (Ed.), Mathematical creativity and mathematical giftedness (pp. 196-198). New York: Springer.

Hartono, R. (2015). Promoting the development of students' individual frame of reference to support length approximation/estimation skills. (Unpublished master dissertation). Sriwijaya University, Palembang.

Hodgson, T., Simonsen, L., Lubek, J., \& Anderson, L. (2003). Measuring Montana: An episode in estimation. In D. H. Clements \& G. Bright (Eds.), Learning and teaching measurement (pp. 221-230). Reston, VA: National Council of Teachers of Mathematics.

Hogan, T. P., \& Brezinski, K. L. (2003). Quantitative estimation: One, two, or three abilities?, Mathematical Thinking and Learning, 5(4), 259-280.

$\mathrm{Hu}, \mathrm{H}$. (2019). Implementing resilience recommendations for policies and practices in gifted curriculum. Roeper Review, 41(1), 42-50.

Jones, G., Taylor, A., \& Broadwell, B. (2009). Estimating linear size and scale: Body rulers. International Journal of Science Education, 31(11), 1495-1509. 
Jones, M. G., Gardner, G. E., Taylor, A. R., Forrester, J. H., \& Andre, T. (2012). Students' accuracy of measurement estimation: Context, units, and logical thinking. School Science and Mathematics, 112(3), 171-178.

Joram, E., Gabriele, A. J., Bertheau, M., Gelman, R., \& Subrahmanyam, K. (2005). Children's use of the reference point strategy for measurement estimation. Journal for Research in Mathematics Education, 36(1), 4-23.

Karp, A. (2017). Some thoughts on gifted education and creativity. ZDM Mathematics Education, 49, 159-168.

Kılıç, Ç., \& Olkun, S. (2013). Primary school students' measurement estimation performance and strategies they used in real life situations. Elementary Education Online, 12(1), 295307.

Leikin, R. (2011). The education of mathematically gifted students: Some complexities and questions. The Mathematics Enthusiast, 8(1-2), 167-188

Leikin, R., Koichu, B., Berman, A., \& Dinur, S. (2017). How are questions that students ask in high level mathematics classes linked to general giftedness? ZDM Mathematics Education, 49, 65-80.

Lemonidis, C., \& Likidis, N. (2019). An integrated hierarchical model of 5th grade students' computational estimation strategies. International Journal of Mathematical Education in Science and Technology, 1-23.

Liu, F. (2009). Multiplication estimation by third and fifth-grade Chinese students. School Science and Mathematics, 107(9), 325-337.

Liu, P. H., \& Niess, M. L. (2006). An exploratory study of college students' views of mathematical thinking in a historical approach calculus course. Mathematical Thinking and Learning, 8(4), 373-406.

Mcmillan, H. J., \& Schumacher, S. (2010). Research in education. Boston, USA: Pearson Education.

Meissner, H. (2000, July-August). Creativity in mathematics education. Paper presented at the meeting of the International Congress on Mathematical Education, Tokyo, Japan.

Miles, M. B., Huberman, A. M., \& Saldana, J. (2014). Qualitative Data Analysis. CA:SAGE.

Ministry of National Education [MoNE]. (2018). Matematik dersi öğretim programı (Illkokul ve ortaokul 1, 2, 3, 4, 5, 6, 7 ve 8. siniflar) [Mathematics curriculum (Primary and secondary 1, 2, $3,4,5,6,7$, and 8 grades)]. Ankara: MEB Publ.

Montague, M., \& van Garderen, D. (2003). A cross-sectional study of mathematics achievement, estimation skills, and academic self-perception in students of varying ability. Journal of Learning Disabilities, 36, 437- 448.

Möhring, W., Frick, A., \& Newcombe, N. S. (2018). Spatial scaling, proportional thinking, and numerical understanding in 5- to 7-year-old children. Cognitive Development, 45, 57-67.

National Council of Teachers of Mathematics (2000). Principles and standards for school mathematics. Reston, VA: National Council of Teachers of Mathematics. 
Nolte, M. (2018). Twice-exceptional students: Students with special needs and a high mathematical potential. In F. M. Singer (Ed.), Mathematical creativity and mathematical giftedness (pp. 199-225). New York: Springer.

Özçelik, T. (2017). Üstün yetenekli öğrencilere yönelik geliştirilen farklılaştırılmış matematik dersi öğretim programının etkililiği [Efficiency of differentiated mathematics curriculum designed for gifted and talented students] (Unpublished doctoral dissertation). Hacettepe University, Ankara.

Patkin, D., \& Gazit, A. (2013). On roots and squares-estimation, intuition and creativity. International Journal of Mathematical Education in Science and Technology, 44(8), 1191-1200.

Patton, M. Q. (2002). Qualitative research and evaluation methods (3rd ed.). California: Sage.

Pitta-Pantazi, D., Kattou, M., \& Christou, C. (2018). Mathematical creativity: Product, person, process and press. In F. M. Singer (Ed.), Mathematical creativity and mathematical giftedness (pp. 27-53). New York: Springer.

Renzulli, J. S. (1986). The three ring conception of giftedness: A developmental model of creative productivity. In Sternberg, R. J. \& Davidson, J. E. (Eds.), Conceptions of Giftedness (pp. 5392). New York, Cambridge University Press.

Renzulli, J. S. (2012). Reexamining the role of gifted education and talent development for the 21st century: A four-part theoretical approach. Gifted Child Quarterly, 56(3), 150-159.

Segovia, I., \& Castro, E. (2009). Computational and measurement estimation; curriculum foundations and research carried out at the University of Granada. Electronic Journal of Research in Educational Psychology, 7(1), 499-536.

Sheffield, L. J. (2018). Commentary paper: a reflection on mathematical creativity and giftedness. In F. M. Singer (Ed.), Mathematical creativity and mathematical giftedness (pp. 405-428). New York: Springer.

Singer, F. M., Sheffield, L., Freiman, V., \& Brandl, M. (2016). Research on and activities for mathematically gifted students. New York: Springer Nature.

Singh, P., Rahmanb, N. A., Ramlyc, M. A., \& Hoon, T. S. (2019). From nonsense to number sense: Enumeration of numbers in math classroom learning. The European Journal of Social and Behavioural Sciences, 25, 2933- 2947.

Smedsrud, J. (2018) Mathematically gifted accelerated students participating in an ability group: A qualitative interview study. Front. Psychol., 9, 1-12.

Sowder, J. T. (1992). Estimation and number sense. In D. A. Grouws (Ed.), Handbook of research on mathematics teaching and learning (pp. 371 -389). New York: Macmillan.

Sriraman, B., \& Knott, L. (2009). The mathematics of estimation: Possibilities for interdisciplinary pedagogy and social consciousness. Interchange, 40(2), 205-223.

Starko, A. (2005). Creativity in the classroom: Schools of curious delight (3rd ed.). Mahwah, NJ: Lawrence Erlbaum Associates.

Subotnik, R. F., Olszewski-Kubilius, P., \& Worrell, F. C. (2011). Rethinking giftedness and gifted education: A proposed direction forward based on psychological science. Psychological Science In The Public Interest, 12(1), 3-54. 
Torrance, E. P. (1974). Torrance tests of creative thinking: Norms-technical manual. Lexington, MA: Ginn.

Usiskin, Z. (2000). The development into the mathematically talented. The Journal of Secondary Gifted Education, 11, 152-162.

Usta, N. (2018). The prospective teachers' skills of identifying students' mistakes about the topic "measures" and their suggestions for eliminating the mistakes. Journal of Computer and Education Research, 6(12), 247-284.

van de Walle, J. A., Karp, K. S., \& Williams, J. M. B. (2016). Elementary and middle school mathematics. Teaching developmentally. Boston: Pearson.

Wang, J. J., Halberda, J., \& Feigenson, L. (2017). Approximate number sense correlates with math performance in gifted adolescents. Acta Psychologica, 176, 78-84.

Yin, R. K. (2017). Case study research and applications: Design and methods. Sage publications.

Yun-hing, L. (2007). The relationship between numerical estimation and number sense in students' learning of mathematics. (Unpublished Master of Dissertation). The University of Honkong, Hongkong. 